Final manuscript

(published in Journal of Nuclear Materials, Vol. 444 (2014) pp. 30-34)

\title{
Oxidation Induced Localized Creep Deformation in Zircaloy-2
}

\author{
Pia Tejland ${ }^{1,2}$ and Hans-Olof Andrén ${ }^{2}$ \\ ${ }^{1}$ Currently at Studsvik Nuclear AB, SE-611 82 Nyköping \\ ${ }^{2}$ Department of Applied Physics, Chalmers University of Technology, \\ SE-412 96 Göteborg, Sweden
}

Corresponding author: P. Tejland pia.tejland@studsvik.se, Phone +46 1552211 70, Fax +46155263156

\begin{abstract}
Extensive plastic deformation in the metal underneath the oxide scale in autoclave tested Zircaloy-2 was studied using transmission electron microscopy (TEM). It was concluded that the plastic deformation is created by creep during oxidation, and is not caused by surface treatment, sample preparation or cooling from autoclave temperatures. Evidence of large strains was found in the form of dislocation tangles, dislocation patches and sub-grain formation, and also indications of twinning were found. The heavily deformed layer is around a few $\mu \mathrm{m}$ thick and no obvious difference could be seen between alloys with different strength or different oxide thickness.
\end{abstract}

Keywords: Zircaloy-2; creep; deformation; oxidation; TEM

\section{Introduction}

Zirconium alloys are used in fuel cladding tubes in nuclear reactors, with the main advantage being their low absorption of thermal neutrons. The corrosion resistance is acceptable, but the aggressive environment in the reactor, with high temperature water and the presence of radiation, still causes the metal to oxidize. This oxidation 
eventually leads to a degradation of mechanical properties due to the ingress of hydogen and a decrease in thermal conductivity due to the growth of oxide, thereby limiting higher fuel burnup. It is therefore important to try to understand the oxidation process in order to find ways to slow it down. Many studies have been conducted treating different aspects of the oxidation process of zirconium alloys. One way of performing research is by studying the metal, oxide and metal/oxide interface using transmission electron microscopy (TEM). With the introduction of the focused ion beam (FIB) in situ lift-out technique for specimen preparation [1], the possibility to investigate large areas with uniform thickness has led to new discoveries, mainly regarding the interface morphology and crack formation [2-10]. However, one aspect that has not yet been investigated using TEM is the creep deformation of the metal underneath the oxide scale.

Oxidation of zirconium alloys leads to a large volume increase (with a PillingBedworth ratio of 1.55 [11]), most of which is in the form of an expansion in the growth direction of the oxide, i.e. perpendicular to the surface of the tube. This expansion is easily accommodated since it is connected to a free surface. However, a small part of the volume increase leads to an expansion (0.5\%) in the axial and hoop directions, i.e. along the metal/oxide interface and perpendicular to the oxide growth direction [12]. This latter expansion is not as easily accommodated as the former one; instead it causes compressive stresses to be built up in the oxide and tensile stresses in the metal matrix. If the metal/oxide interface were flat, rather small tensile stresses would be expected in the metal, since the thickness of the metal layer is much larger than the thickness of the oxide layer. However, in reality the interface is undulated with a wavelength of around $1 \mu \mathrm{m}$ and an amplitude of a few hundred nm [9,13-17]. Parise et al. have made calculations for this case and found that very large stresses may exist in the metal close to $(<1 \mu \mathrm{m})$ the interface, both along the interface and perpendicular to it, causing the metal to deform plastically (using a visco-plastic model for the zirconium alloy) [12].

Indeed, when conducting TEM studies of the metal/oxide interface in Zircaloy-2, evidence of heavy plastic deformation can be found in the metal underneath the oxide scale. If this deformation has occurred during the oxidation process the strain rate 
must have been so small that we should regard it as a creep process, involving both dislocation glide and climb. In this study the deformation of the metal will be investigated and discussed in detail and the influence this deformation might have on the oxidation behavior of the material will be addressed.

However, before studying the deformation in detail, the origin of the deformation must first be confirmed to really come from oxidation. The proposed origin of the deformation (i.e. it stems from stresses caused by oxidation) has not been confirmed. There may also be other explanations for the observed plastic deformation, such as the deformation being created during (i) TEM sample preparation, (ii) surface treatment (grinding) of the tubes and (iii) cooling from autoclave temperature down to room temperature. Within this study, a systematic investigation has been performed to prove that the deformation really comes from the oxidation process and that the other possible explanations can be dismissed.

\section{Experimental details}

\subsection{Materials}

Zircaloy-2 is a material that is and has been extensively used in boiling water reactors (BWRs). For this study two different commercial Zircaloy-2 alloys were chosen, for which there exist long-term in-pile data. The two materials have approximately the same chemical composition, as can be seen in Table 1. They do, however, exhibit substantially different oxidation behavior, both in-pile and in steam autoclave tests. This difference is mainly associated with their different second phase particle (SPP) size distribution. Due to different final heat treatments, Material A contains smaller but more numerous SPPs while Material B contains larger but fewer SPPs. The average SPP diameters can be found in Table 1. Both materials were in the form of recrystallized cladding tubes. For more detailed information about the studied materials, see Ref [9]. The materials were thus chosen to isolate the influence of a difference in SPP size distribution on the oxidation process in Zircaloy-2. 
In addition to influencing the oxidation behavior of the materials, the difference in SPP size also affects the mechanical properties, since a material with more numerous particles will be stronger and more difficult to deform plastically than a material with fewer and larger particles; a hardening mechanism known as particle hardening. This means that Material A has higher values of both yield stress and fracture stress than Material B; the results from tensile testing performed at $300^{\circ} \mathrm{C}$ are displayed in Table 1. It should be noted that most of the difference in yield stress stems from the difference in particle hardening, since the solid solution hardening effect of a slightly higher tin content in Material A is rather small. Isobe and Matsuo measured the yield stress at room temperature in $\mathrm{Zr}-0.2 \mathrm{Fe}-0.1 \mathrm{Cr}-0.5 \mathrm{Nb}$ alloys with different tin contents and found an increase in yield stress of approximately $95 \mathrm{MPa}$ when the tin content increased from 0.5 to $1.5 \%$ [18]. The $0.14 \%$ higher tin content in Material A would therefore give an increase in yield stress of $13 \mathrm{MPa}$ at room temperature, and less than this at $300^{\circ} \mathrm{C}$. The measured difference of $45 \mathrm{MPa}$ is therefore mainly the result of a difference in particle hardening.

The materials were oxidized in static steam autoclaves at temperatures of 400 and $415^{\circ} \mathrm{C}$ (where the higher temperature was used for obtaining thick oxides within a reasonable time frame) and a pressure of $10.3 \mathrm{MPa}$ from 3 to 150 days to obtain different oxide thicknesses, see Table 2. From this table it is apparent that Material B, with the larger SPPs, has the superior oxidation behavior. Besides the autoclaved materials, with oxide thicknesses of roughly 1, 2, and $9 \mu \mathrm{m}$, also un-oxidized material has been available for observation. In the table all available materials are presented, with the materials shown in figures in this work high-lighted in bold font.

\subsection{TEM}

TEM specimens of the metal/oxide interface were prepared with the focused ion beam (FIB) in situ lift-out technique [9], using an FEI Strata 235 Dual Beam system.

The TEM work was carried out using bright field TEM imaging in a Philips CM 200 microscope. 


\section{Results and discussion}

\subsection{Establishing the origin of the deformation}

\subsubsection{Surface treatment}

In order to establish the starting point of oxidation, the original, un-oxidized surface was investigated. Both the inside and the outside of the tubes have been studied, since they have undergone different surface treatments. The outer surface of the tubes has been ground, and this grinding gives rise to some plastic deformation. Evidence of such deformation is shown in Fig. 1, where a high dislocation density can be observed to a depth of roughly $500 \mathrm{~nm}$. The inner surface of the tubes has been pickled, a treatment that does not give rise to any plastic deformation. No evidence of plastic deformation can be seen in Fig. 2, where a specimen from the inner tube surface is displayed. Only some contrast from light radiation damage is visible; it is due to the ion milling used for specimen preparation.

If the observed plastic deformation did only come from the surface treatment (grinding) of the tubes, there should be no deformation when the oxide has consumed the deformed part, i.e. when the oxide is thicker than $500 \times 1.54=775 \mathrm{~nm} \approx 0.8 \mu \mathrm{m}$ (1.54 is the volume expansion perpendicular to the metal/oxide interface upon oxidation [12]). However, when studying samples from the outer surface of Material B with $1 \mu \mathrm{m}$ thick oxide, there is still a lot of plastic deformation, as can be seen in Fig. 3.

\subsubsection{Specimen preparation}

The oxide is in compression when attached to the tube, but when a thin foil is lifted out (as is the case in the FIB in-situ lift-out technique that was used for preparing the TEM specimens) the oxide is free to expand. This expansion might then be the cause of the deformation in the metal. In order to test whether this scenario was likely, the oxide was removed from one sample, by ion milling in the FIB, before cutting out the TEM specimen. The result is that there is still a lot of deformation under where the oxide used to be (Fig. 4). Since the oxide was removed, no tensile stresses exist in the 
oxide that will cause plastic deformation in the metal, so the deformation cannot have appeared according to the described scenario.

\subsubsection{Cooling}

In order for the present study to be relevant, the plastic deformation must have been caused by oxidation, and not by cooling of the tubes from autoclave temperatures to room temperature. Thus the thermal expansions for both oxide and metal matrix have been considered. The linear thermal expansion coefficient for monoclinic $\mathrm{ZrO}_{2}$ is $8 \times$ $10^{-6} /{ }^{\circ} \mathrm{C}$ [19] and for Zircaloy-2 it is $5.67 \times 10^{-6} /{ }^{\circ} \mathrm{C}$ [20]. Cooling from autoclave temperature $\left(400 / 415^{\circ} \mathrm{C}\right)$ to room temperature $\left(25^{\circ} \mathrm{C}\right)$ will thus cause a somewhat larger contraction in the oxide of $(8-5.67) \times 10^{-6} \times(400-25)=0.84 \times 10^{-3}$ or $(8-$ $5.67) \times 10^{-6} \times(415-25)=0.87 \times 10^{-3}$, respectively. Even if all this strain is localized in the metal, i.e. around $0.09 \%$ compression, it is below the strain level needed to plastically deform a metal, as the yield stress usually corresponds to a strain level of $0.2 \%$. Thermal expansion will therefore not cause sufficient stress for plastic deformation to occur in the metal.

One factor that might increase the difference in expansion between the oxide and the metal is the fact that the expansion of the oxide is anisotropic, meaning that in some directions the expansion might be larger than the average value. However, the direction with the largest expansion contribution is the $c$-direction, i.e. in most oxide grains the direction perpendicular to the metal/oxide interface (since the oxide consists of columnar grains with their c-axis oriented within $20^{\circ}$ of this direction [21]).

In conclusion, the observed large plastic deformation cannot possibly be a result of cooling from autoclave temperatures to room temperature.

\subsection{Different types of deformation}

The high dislocation density found using BF TEM is evidence of deformation to a high strain. Very few areas containing individual dislocations are found; instead the dislocations have formed structures such as dislocation tangles, dislocation patches or sub-grain boundaries. Also indications of twinning can be found. 
When dislocations moving in a material come across some obstacle, such as a grain boundary or a particle, they can get tangled together and form dislocation tangles. As deformation continues, these areas will have an increasing dislocation density, and dislocation patches are formed, i.e. areas of very high dislocation density. Such areas of dislocation patches are found predominantly in Fig.1 and in Fig. 3 (marked in white), but can be seen in almost all micrographs to different extents.

The grain size of both materials has been measured to an average of $4 \mu \mathrm{m}$. This value does not change depending on location in the tube, i.e. it is the same in the middle of the tube and close to the tube walls. Despite this fact, the grain size that can be seen in the metal close to the metal/oxide interface seems to be substantially smaller than $4 \mu \mathrm{m}$. This is an indication of sub-grain formation, and in Fig. 5 the grain boundaries of such sub-grains can be seen clearly in the positions marked with arrows. Fig. 6 also shows the formation of sub-grains, indicated by arrows in the bright metal grain. These sub-grains form predominantly in the metal grains closest to the metal/oxide interface, due to the very high strain in this area.

Since zirconium has a hexagonal structure, twinning is a possible deformation mechanism. One example of what appears to be twinning is found in Fig. 7.

It is not surprising to find the above-described dislocation structures, since the stresses in the metal have been shown to be high. In a paper by Parise et al. the stress distribution close to the undulating metal/oxide interface was calculated using a viscoplastic model for the Zircaloy-4 metal at $350^{\circ} \mathrm{C}$ and it was found that there are considerable stresses in the metal leading to large plastic strains. For a wavelength of $1 \mu \mathrm{m}$ and a wave amplitude of $100 \mathrm{~nm}$ the radial stress reaches a maximum value of over $1000 \mathrm{MPa}$ closest to the interface beneath a wave crest (delayed part of the metal/oxide interface), falling to $100 \mathrm{MPa}$ at $0.8 \mu \mathrm{m}$ from the interface. The maximum visco-plastic strain in the metal was $18 \%$, about $200 \mathrm{~nm}$ below a wave crest [12].

\subsection{Comparison of different oxide thickness}


The zone of plastic deformation is several $\mu \mathrm{m}$ deep, extending at least through the grains connected to the metal/oxide interface. A comparison of the deformation depth has been performed for different oxide thicknesses. The result shows no significant difference, the deformation depth seems to be more related to the metal grains and their orientation.

\subsection{Comparison of different materials}

Since Material A has higher yield strength than Material B, mainly due to particle hardening, it might be expected that the deformation structure such as dislocation distribution and sub-grain size should be different. However, this was very difficult to see in BF TEM images, since the contrast is very complex and a small difference in deformation structure is hard to detect. When choosing images to present here, the most representative micrographs of each phenomenon were chosen, and images from both Material A and Material B are therefore shown in the figures.

\subsection{Relation to the oxygen-enriched zone}

Like in all zirconium alloys, an oxygen-enriched zone is expected to form in Materials $\mathrm{A}$ and $\mathrm{B}$ during oxidation. At the metal/oxide interface the metal is saturated with oxygen, which means that the oxygen content is around 30 at. \%, and from the interface an oxygen diffusion profile extends into the metal. We have measured the width of this diffusion profile (one diffusion length, i.e. the distance from the interface to a point where the oxygen content is $16 \%$ of the value at the interface) in Material B, oxidized in a steam autoclave at $400^{\circ} \mathrm{C}$ to an oxide thickness of $1 \mu \mathrm{m}$ [22]. The width was found to be 100-220 nm wide, the exact value depending on position relative to the undulating metal/oxide interface - a larger value was found at wave crests than at wave valleys [22]. This is a much narrower zone than the several $\mu \mathrm{m}$ wide zone of plastic deformation treated in this paper.

The oxygen-enriched zone is expected to be very hard. Substantial solid solution hardening is achieved in many commercial zirconium alloys by the addition of only around 1 at. \% oxygen, and Béranger and Lacombe found an increase of the micro- 
hardness of pure zirconium of at least a factor of 3 close to the metal/oxide interface [23]. However, there is no obvious difference in the appearance of the dislocation structure close to the metal/oxide interface and further away from the interface. Obviously, the metal below the oxygen-enriched zone first deforms, and then the deformed structure with its dislocations and sub-grains is inherited by the inward moving oxygen-enriched zone.

\section{Conclusions}

In this study it has been established that extensive plastic deformation in the metal underneath the oxide scales in Zircaloy-2 is created by creep during oxidation of the material. It is not a result of tube surface treatment, specimen preparation or cooling from autoclave temperatures.

The high strain in the metal is brought about by a high dislocation activity and twinning, leading to the formation of various dislocation structures such as dislocation tangles and patches and sub-grains.

No obvious difference in dislocation sub-structure or twinning can be found when comparing two alloys with different yield strength.

\section{Acknowledgements}

Sandvik Materials Technology is thanked for supplying the materials and performing the autoclave testing. This work was carried out with the support of Westinghouse Electric Sweden AB, Sandvik AB, Vattenfall Nuclear Fuel AB, OKG AB and the Swedish Radiation Safety Authority. 


\section{References}

[1] J. Mayer, L. Giannuzzi, T. Kamino, J. Michael, MRS Bull. 32 (2007) 400407.

[2] S. Abolhassani, R. Restani, T. Rebac, F. Groeschel, W. Hoffelner, G. Bart, W. Goll, F. Aeschbach, J. ASTM Int. 2, (2005) No. 6.

[3] A. Yilmazbayhan, E. Breval, A.T. Motta, R.J. Comstock, J. Nucl. Mater. 349 (2006) 265-281.

[4] D. Hudson, N. Ni, S. Lozano-Perez, D. Saxey, C. English, G.D.W. Smith, J. Sykes, C. Grovenor, in: Proceeedings of 14th International Conference on Environmental Degradation of Materials in Nuclear Power Systems, Virginia Beach, VA, August 23-27, 2009, American Nuclear Society, La Grange Park, IL.

[5] N. Ni, S. Lozano-Perez, M.L. Jenkins, C. English, G.D.W. Smith, J.M. Sykes, C. Grovenor, Scr. Mater. 62 (2010) 564-567.

[6] C. Proff, S. Abolhassani, M.M. Dadras, C. Lemaignan, J. Nucl. Mater. 404 (2010) 97-108.

[7] N. Ni, S. Lozano-Perez, J.M. Sykes, G.D.W. Smith, C.R.M. Grovenor, Corr. Sci. 53 (2011) 4073-7083.

[8] M. Preuss, P. Frankel, S. Lozano-Perez, D. Hudson, E. Polatidis, N. Ni, J. Wei, C. English, S. Storer, K.B. Chong, M. Fitzpatrick, P. Wang, J. Smith, C. Grovenor, G.D.W. Smith, J. Sykes, B. Cottis, S. Lyon, L. Hallstadius, B. Comstock, S. Ambard, M. Blat-Yrieix, J. ASTM Int. 8 (2011), No. 9.

[9] P. Tejland, M. Thuvander, H.-O. Andrén, S. Ciurea, M. Dahlbäck, L. Hallstadius, J. ASTM Int. 8 (2011), No. 6.

[10] P. Tejland, H.-O. Andrén, J. Nucl. Mater. 430 (2012) 64-71.

[11] N.B. Pilling, R.E. Bedworth, J. Inst. Met. 29 (1923) 529-591.

[12] M. Parise, O. Sicardy, G. Cailletaud, J. Nucl. Mater. 256 (1998) 35-46.

[13] H. Blank, G. Bart, H. Thiele, J. Nucl. Mater. 188 (1992) 273-279.

[14] B. Hutchinson, B. Lehtinen, J. Nucl. Mater. 217 (1994) 243-249.

[15] M. Parise, R. Foerch, G. Cailletaud, J. Physique IV 9 (1999) 311-320.

[16] P. Bossis, J. Thomazet, F. Lefebvre, in: G. D. Moan, P. Rudling (Eds.), Proceedings of 13th International Symposium on $\mathrm{Zr}$ in the Nuclear Industry, 
ASTM-STP-1423, ASTM International, West Conshohocken, PA, 2002, pp. $190-221$.

[17] A.T. Motta, M.J. Gomes da Silva, A. Yilmazbayhan, R.J. Comstock, Z. Cai, B. Lai, J. ASTM Int. 5, (2008), No. 3.

[18] T. Isobe, Y. Matsuo, in: C. M. Eucken, A. M. Garde (Eds), Proceedings of 9th International Symposium on Zirconium in the Nuclear Industry, ASTM-STP1132, ASTM International, West Conshohocken, PA, 1991, pp. 346-367.

[19] R.N. Patil, E.C. Subbaro, J. Appl. Cryst. 2 (1969) 281-288.

[20] W.F. Gale, T.C. Totemeier, (Eds.), Smithells Metals Reference Book, eighth ed., Elsevier, Amsterdam, 2004.

[21] C. Li, R. Zuo, Z. Li, S. Ying, B. Shen, Thin Solid Films 461 (2004) 272-276.

[22] P. Tejland, H.-O. Andrén, G. Sundell, M. Thuvander, B. Josefsson, L. Hallstadius, M. Ivermark, M. Dahlbäck, "Oxidation Mechanisms in Zircaloy-2 - The Effect of SPP Size Distribution", Proceedings of the 17th International Symposium on Zirconium in the Nuclear Industry, in press.

[23] G. Béranger, P. Lacombe, J. Nucl. Mater. 16 (1965) 190-207. 


\section{Tables}

Table 1. Chemical composition, average SPP size and mechanical properties (from tensile testing at $300^{\circ} \mathrm{C}$ ) of the two studied Zircaloy-2 materials. Data provided by the manufacturer, Sandvik AB, except for average SPP size that was determined in [10].

\begin{tabular}{|c|c|c|}
\hline & Material A & Material B \\
\hline \multicolumn{3}{|l|}{ Chemical composition } \\
\hline Sn (\%) & 1.46 & 1.32 \\
\hline $\mathrm{Fe}(\%)$ & 0.12 & 0.17 \\
\hline $\mathrm{Cr}(\%)$ & 0.10 & 0.10 \\
\hline Ni (\%) & 0.05 & 0.05 \\
\hline $\mathrm{Si}(\mathrm{ppm})$ & 80 & 70 \\
\hline $\mathrm{O}(\mathrm{ppm})$ & 1240 & 1300 \\
\hline $\mathrm{N}(\mathrm{ppm})$ & 40 & 50 \\
\hline \multicolumn{3}{|l|}{ SPP size } \\
\hline Average SPP diameter (nm) & 22 & 84 \\
\hline \multicolumn{3}{|l|}{ Mechanical properties } \\
\hline Yield stress (MPa) & 215 & 180 \\
\hline Fracture stress $(\mathrm{MPa})$ & 351 & 320 \\
\hline
\end{tabular}


Table 2. Autoclave data and the resulting weight gains and corresponding oxide thicknesses (calculated assuming that $15 \mathrm{mg} / \mathrm{dm}^{2}$ corresponds to $1 \mu \mathrm{m}$ ).

\begin{tabular}{|c|c|c|c|c|}
\hline Alloy & $\begin{array}{c}\text { Temp } \\
\left({ }^{\circ} \mathrm{C}\right)\end{array}$ & $\begin{array}{c}\text { Time } \\
(\text { days })\end{array}$ & $\begin{array}{c}\text { Weight gain } \\
\left(\mathrm{mg} / \mathrm{dm}^{2}\right)\end{array}$ & $\begin{array}{c}\text { Oxide thickness } \\
(\mu \mathrm{m})\end{array}$ \\
\hline Material A & 400 & 3 & 18.9 & $\mathbf{1 . 3}$ \\
\cline { 2 - 5 } & 400 & 6 & 33.9 & 2.3 \\
\cline { 2 - 5 } & 415 & 30 & 132.5 & 8.8 \\
\hline Material B & 400 & 3 & 15 & $\mathbf{1}$ \\
\cline { 2 - 5 } & 400 & 15 & 27.5 & $\mathbf{1 . 8}$ \\
\cline { 2 - 5 } & 415 & 150 & 135 & $\mathbf{9}$ \\
\hline
\end{tabular}




\section{Figures}

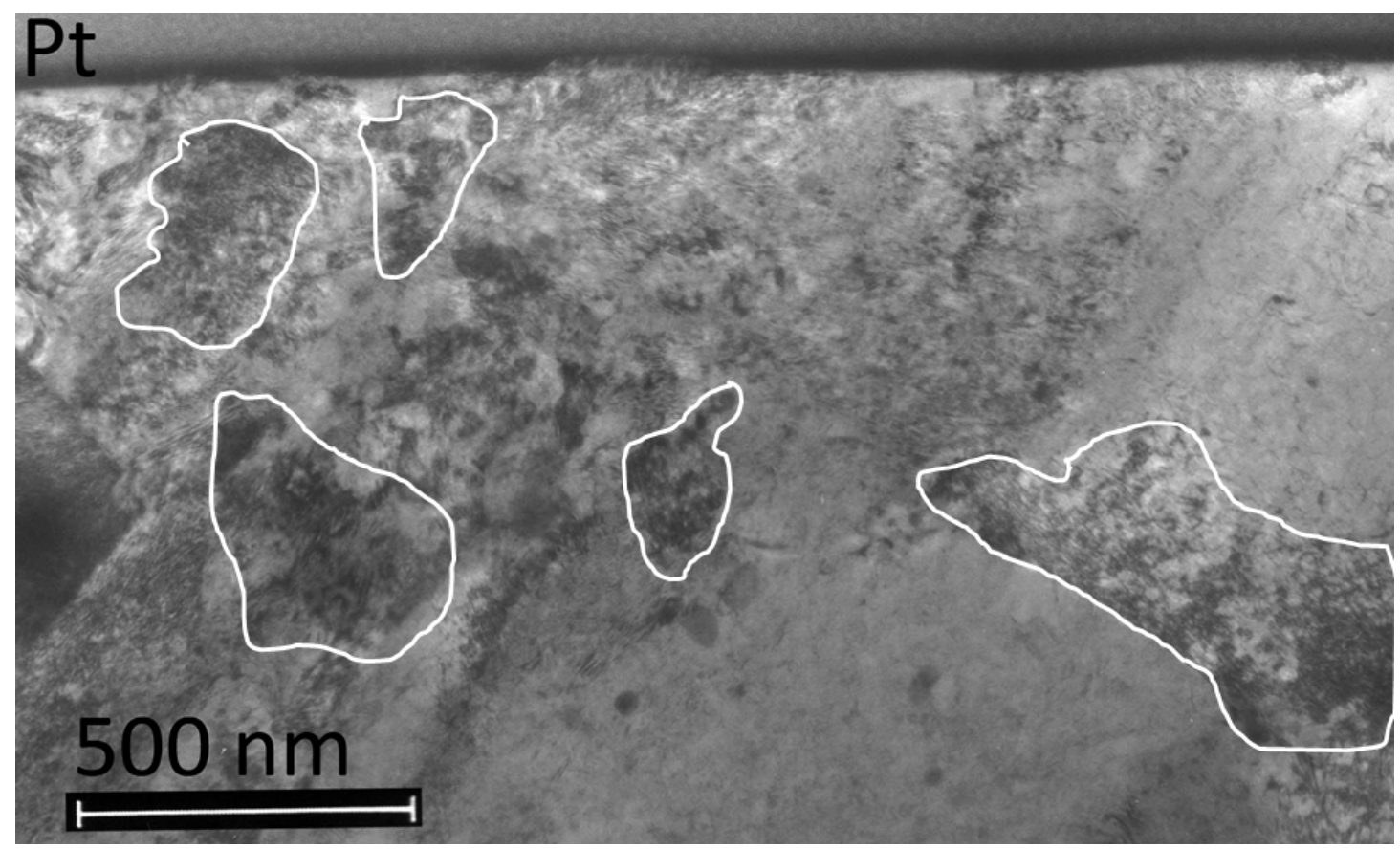

Figure 1. Un-oxidized outer tube surface specimen of Material A. Areas with high dislocation density (dislocation patches) are marked in white.

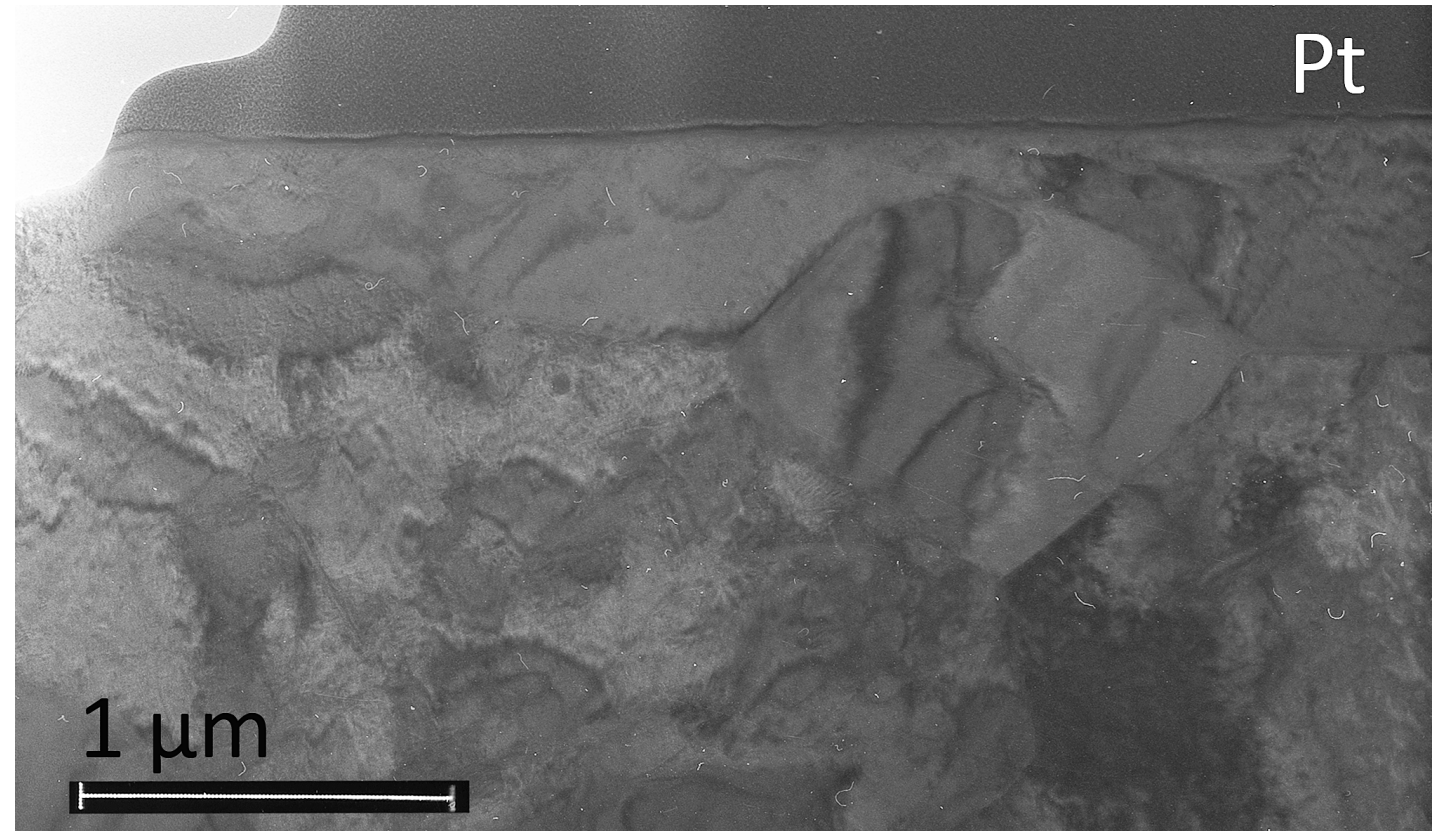

Figure 2. Un-oxidized inner tube surface specimen of Material A. 


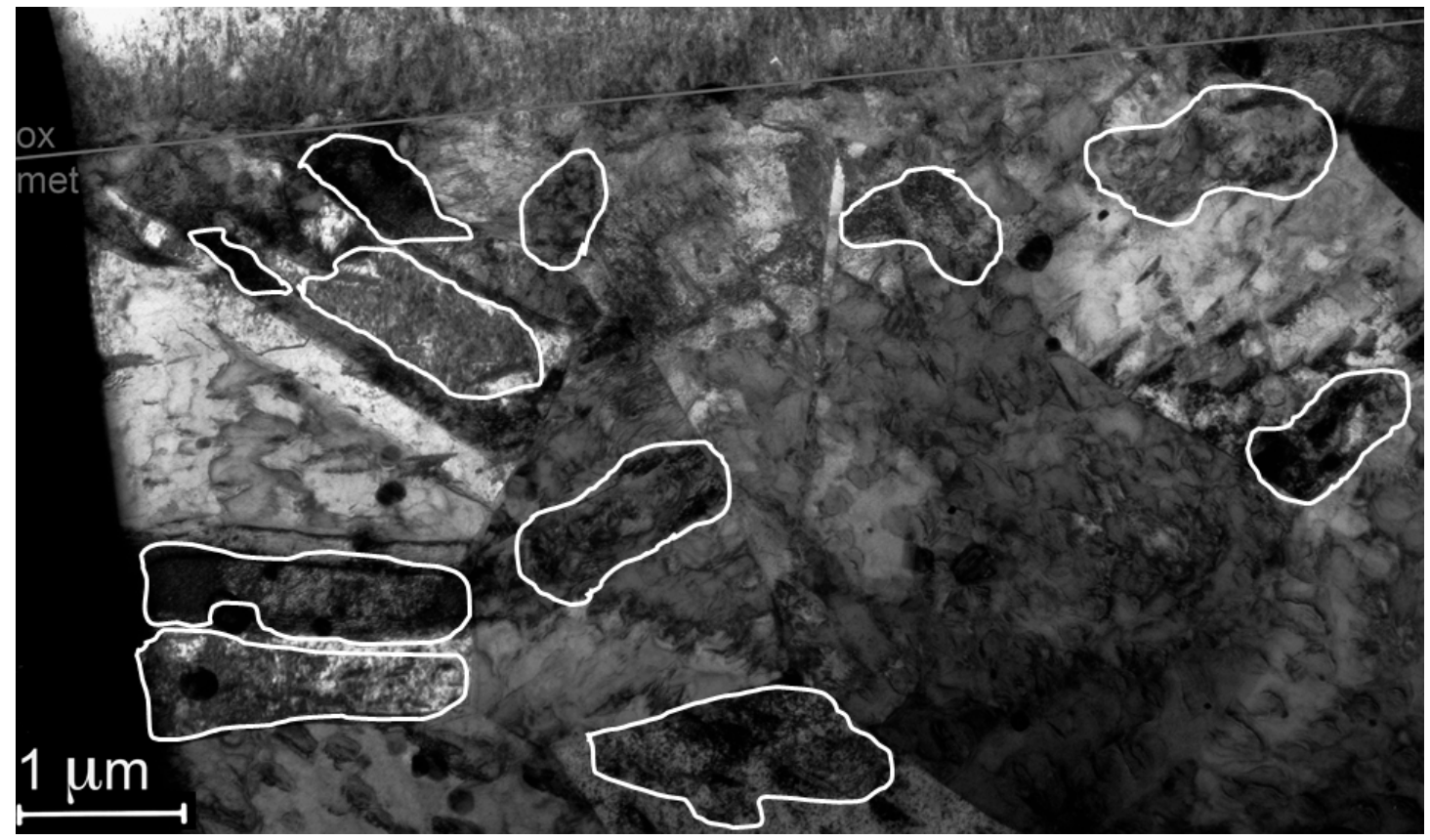

Figure 3. Material $\mathrm{B}$ with $1 \mu \mathrm{m}$ thick oxide. Some of the areas with dislocation patches are marked in white.

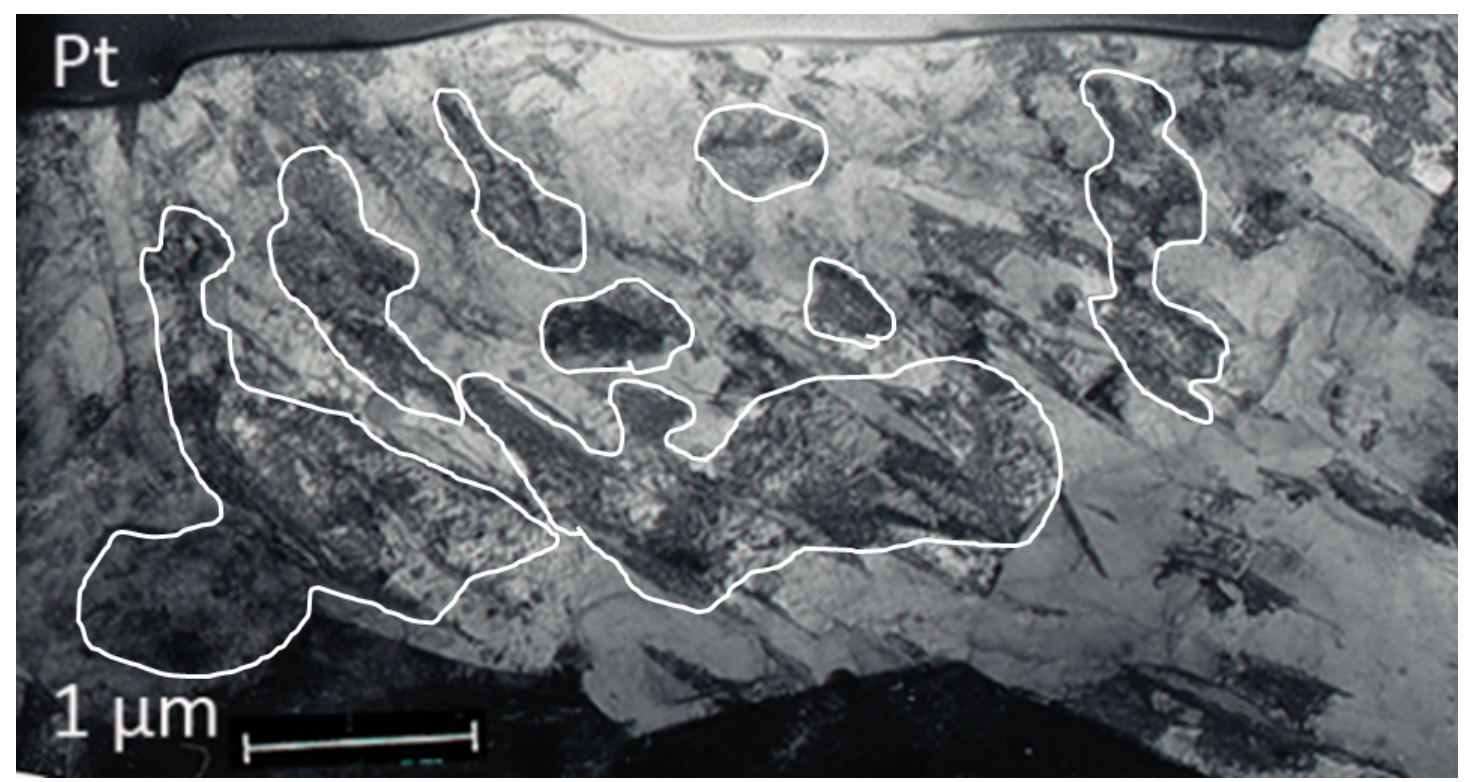

Figure 4. Material $\mathrm{B}$ with the $1 \mu \mathrm{m}$ thick oxide scale removed before sample preparation. Areas with high dislocation density are marked in white. 


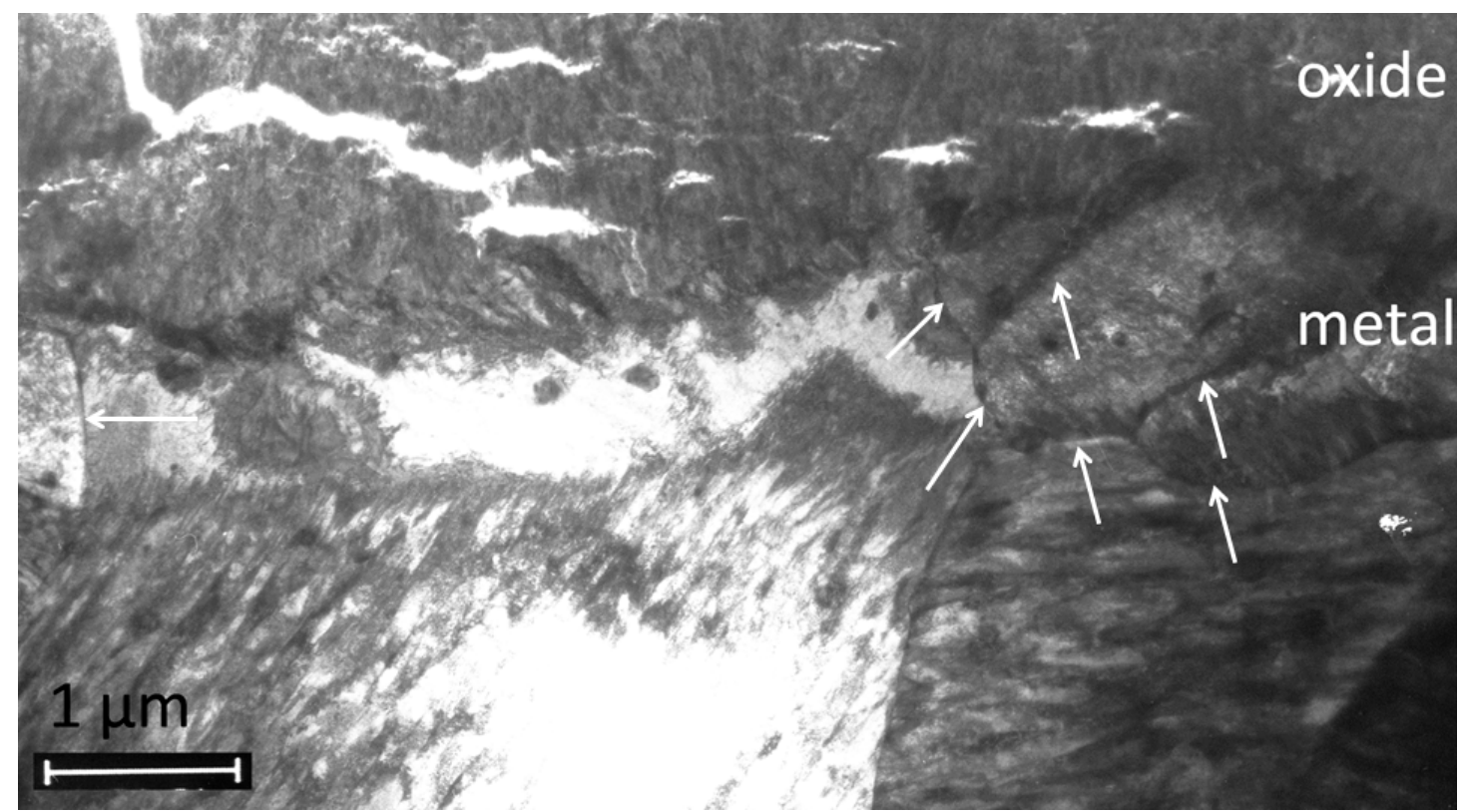

Figure 5. Sub-grain formation (arrows point at sub-grain boundaries) in Material B with $9 \mu \mathrm{m}$ thick oxide.

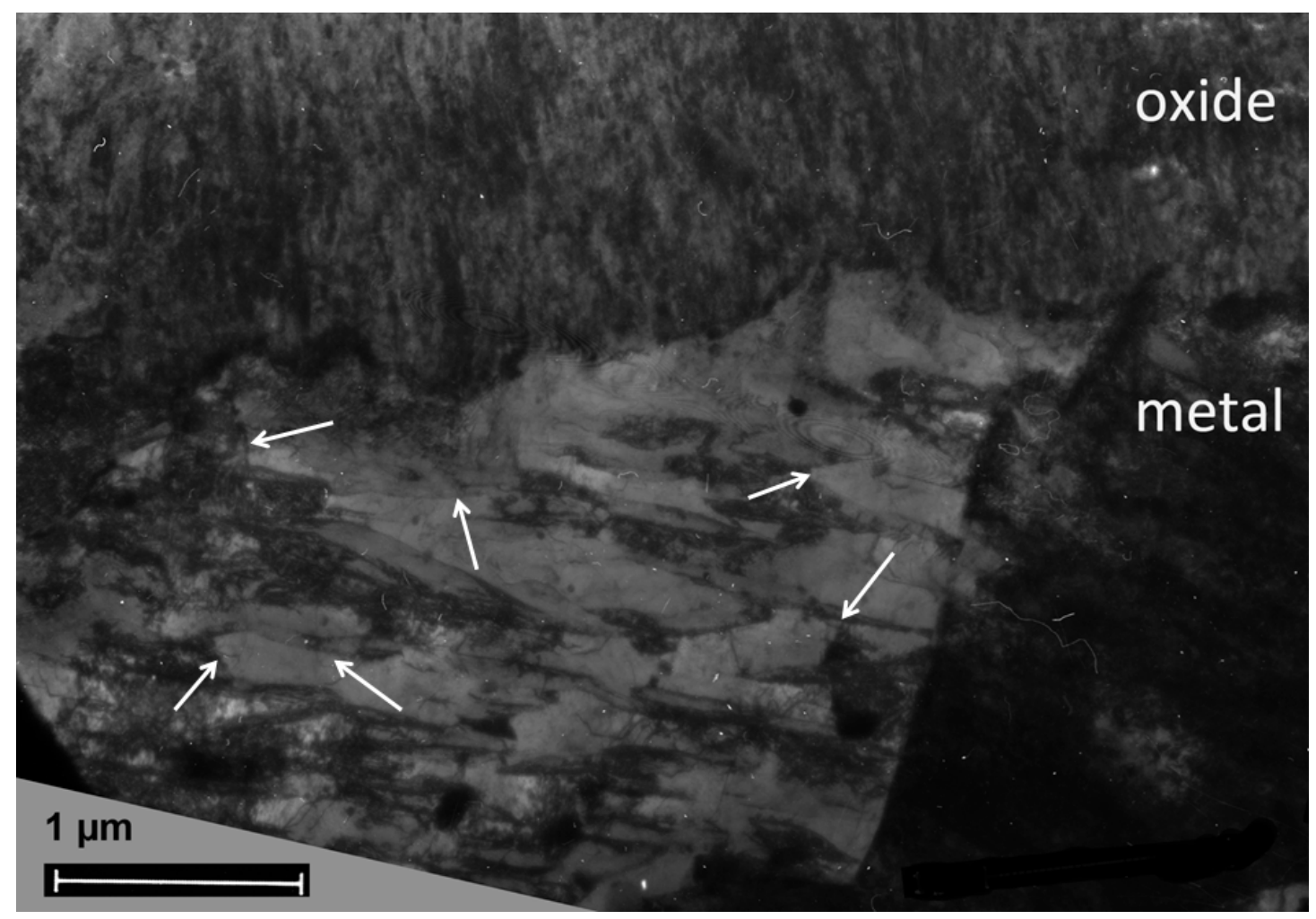

Figure 6. Sub-grain formation (arrows point at sub-grain boundaries) in Material B with a $2 \mu \mathrm{m}$ thick oxide scale. 


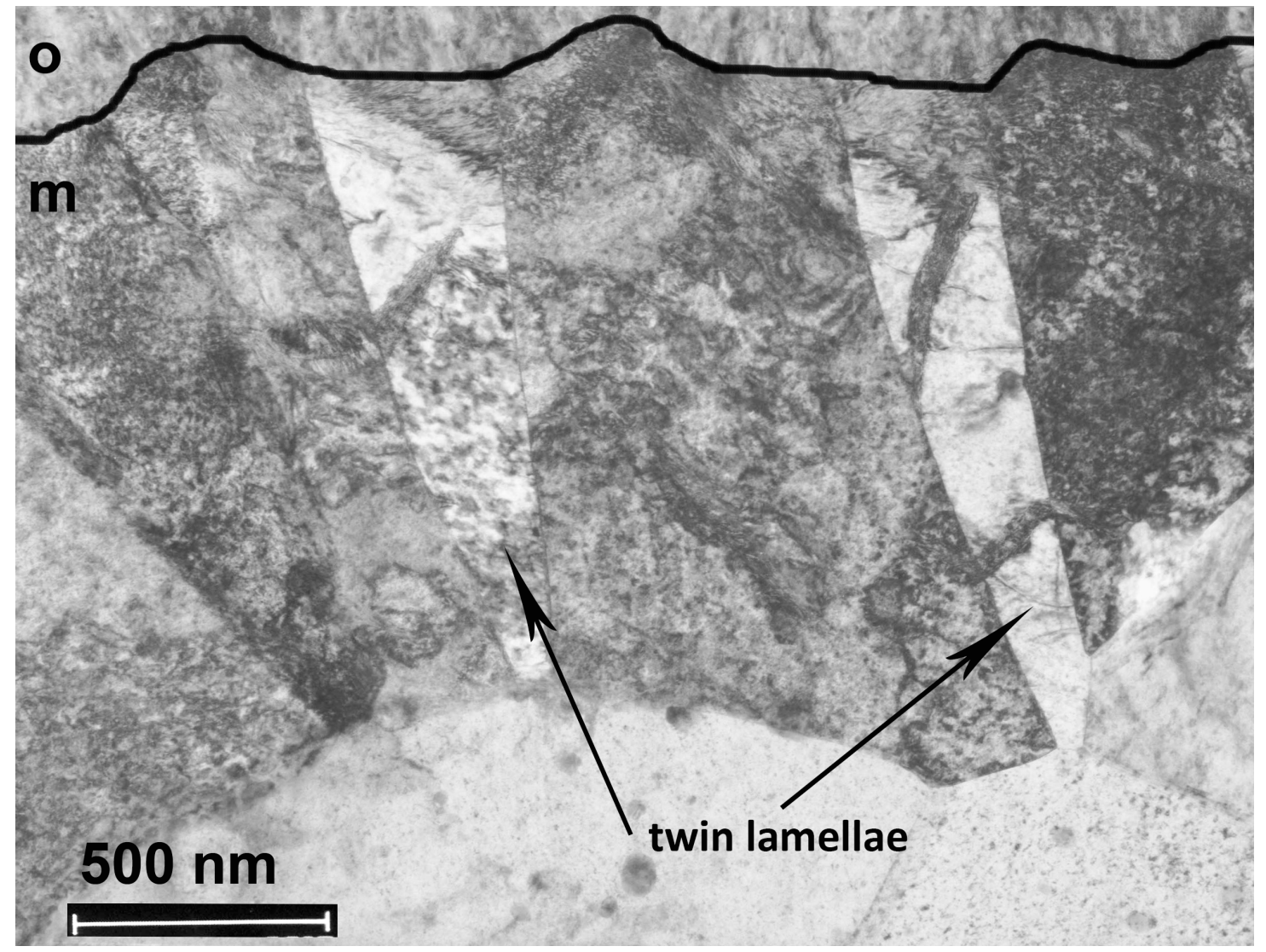

Figure 7. Twinning in Material A with $1 \mu \mathrm{m}$ thick oxide. Arrows point towards two twin lamellae. 